\title{
A case study in the textile industry for the reduction of cost of quality
}

\author{
Muhammad Rehan Yasin ${ }^{1}$, M Nasir Bashir ${ }^{2}{ }^{*}$, Syed Asad Ali Zaidi ${ }^{3}$ \\ 1, 2, 3 Department of Industrial and Manufacturing Engineering, PN Engineering College, National University of \\ Science \& Technology, Karachi 75350, Pakistan
}

Keywords
Pakistan
Textile
Quality cost
Quality costing
Terry
Towel
Dyeing
Printing
Stitching
Weaving
Cost of Quality (CoQ)

Received: 2 October 2019

Accepted: 6 November 2019

Published: 23 December 2019

\begin{abstract}
Nowadays, textile industries are working to maximize profit by using lean tools. This paper describes various Cost of Quality procedures to determine COQ in the organization. Still, it was felt that it could be improved and simplified to make a standard format for finding quality for different departments. A Quality Cost procedure was refined and implemented in the textile industry. COQ program was implemented in the production department of a textile product manufacturer. Prevention, Appraisal, Failure \& Opportunity Cost model was employed. The total COQ of the manufacturing textile unit was $6.8 \%$ concerning sales, which was later reduced to $4.5 \%$ after implementing lean and sustainable initiatives. The cost of quality was calculated for four departments. Internal failure is found to the maximum in all the departments. The major reason for high internal failure cost is the production loss (Target unachieved). There is a huge gap in the implementation and understanding of COQ concepts in the textile industries in Pakistan. This paper provides awareness to calculate COQ in the textile sector for all developing countries. The same procedure for COQ calculation can be followed in any textile industry, and COQ can be reduced easily.
\end{abstract}

\section{INTRODUCTION}

Customers always attract to those suppliers who promise to give high quality. In this era of competition, not only in textile sector, every sector is striving to attain the best level of quality so that they can grab their target market. The study concluded that if we increase product quality, that means we had to increase product manufacturing cost. For this purpose, measuring cost of quality is important [1]. It is evident that many industries in Pakistan are devoid of formal Quality Costing system. However, the will to implement best practices to control quality cost does exist up to some extent. The current situation of the textile sector in Pakistan shows that they need training in Cost of Quality for better understanding and implementation [2]. Organizations always find ways that are precise and easy. In this paper, sev- eral costing models were evaluated $[3,4,5,6,7,8,9,10]$, but some of them are too lengthy and sophisticated, few of them are not expressed as a formal document $[3,4,5,6,7,8,9]$. The textile industry is contributing more than $60 \%$ of exports to Pakistan. As Pakistan is an agricultural country, there is no substitutefor Pakistan's economy other than the textile industry. The main roots of textile are cotton products, and we are the fourth-largest producer of cotton in the world. Since textile products are manufactured in Pakistan, so we are getting cheap raw material as compared with other sectors due to no imports. It is also a great source of creating new employment opportunities. $38 \%$ of the labor force work in the textile industry. The textile industry enjoys cheap labor, and it also reduces poverty. The top buyers of Pakistani textile goods are USA, Japan, Korea, Saudi Ara-

\footnotetext{
${ }^{*}$ Corresponding author: M Nasir Bashir

†email: nasir@pnec.nust.edu.pk
} 
bia, Italy, Turkey, Canada, Sweden, Australia, EU, Gulf region, UK, Hong Kong, etc. The textile industries have been playing a phenomenal role in earning foreign exchange. Pakistan is facing a huge challenge from its competitors like India, Bangladesh, China, Sri-Lanka and Vietnam. Because there are several lacking in Pakistani textiles; some of them are as follows:

1. Due to a lack of research and development in textile, Pakistan lost opportunities to utilize raw material more properly.

2. Due to lack of technology, textiles in Pakistan also using massive manpower, and sometimes the child labor ratio is also increasing in Pakistan.

3. The major problem which textile industries are facing in Pakistan is the energy crisis. Load Shedding occurs very often; many industries convert their plant to gas, but unfortunately, gas load shedding also started in the last few years due to which industries close their units.

4. Due to the poor law and order situation, investors are reluctant to invest in Pakistan. They usually prefer some other countries where they can get maximum profit.

5. Due to poor coordination with farmers and delivering them money on time by some investors, they are not interested in cotton farming. They are usually interested in sugarcane and maize farming.

6. Due to the lack of skilled labor, customers are not getting quality products. The higher management of the textile mills usually wants illiterate workers to maintain international machinery.

7. Due to using outdated machinery, the world customers do not encourage Pakistani industries. They prefer advanced countries because they are using advanced machinery [11]. 8. Due to a lack of Professional Planners, Pakistani Textile bears a huge inventory cost and Quality issues [12].

The ISO certifications are not synchronized with the actual practices within the organizations. There is a need for quality training for better understanding. Proper Check and balance of Quality at every stage required. The involvement of all the departments should be in practice to follow proper SOP of every department [13]. Research shows that the implementation status of COQ (PAF or ABC Model) is inferior to non-existent [12].

According to another research of developing country like Pakistan, it is clearly mentioned that implementation status and understanding level of QMS and COQ concepts in the garment sector is found to be very weak [14]. A study shows that All Pakistan Textile Mills Association (APTMA) member companies adopted ISO 9001 QMS implementation only, and other techniques like Six Sigma are ignored [15]. A sur- vey in Pakistan's knitwear industry found few satisfactory results regarding the basic understanding of COQ and TQM, and some showed limited knowledge of advanced quality concepts [16].

\section{LITERATURE REVIEW}

\section{A. Cost of Quality by Juran and Feigenbaum's}

Juran and Feigenbaum define four Different categories of quality costing (P-A-F approach). These four Costs include Internal Failure Cost, External Failure Cost, Appraisal Cost, and Prevention Cost.

1) Internal failure cost: "These are cost which would disappear if no defects existed in the product before shipment to the customer." According to him, it includes Scrap, Rework, Retest, Downtime, Yield Losses, and Disposition.

2) External failure cost: "These are cost which would disappear if no defects existed in the product before shipment to the customer." According to him, it includes Scrap, Rework, Retest, Downtime, Yield Losses, and Disposition.

3) External failure cost: "These are costs would also disappear if there were no defects. They are distinguished from the internal failure cost by the facts that the defects are found after the shipment to the customers." According to him, it includes complaint adjustment, warranty charges, and allowances.

4) Appraisal cost: "These are costs incurred to discover the condition of the product." According to him, it includes incoming material inspection, inspection, and test, maintaining the accuracy of test equipment, and evaluation of stocks.

5) Preventive cost: "These costs are incurred to keep failure and appraisal costs to a minimum." According to him, it includes quality planning, new-products review, training, process, control, quality data acquisition $\&$ analysis, quality reporting.

These are cost categories experimented in several organizations, and it is followed widely while calculating COQ $[10,17,18,19]$.

\section{B. Cost of Quality by Crosby}

It is concerned with the activity cost, i.e., price of conformance and -non-conformance.

1) Price of conformance: This cost is the cost of good quality, i.e., to ensure the good quality of the product .

2) Price of non-conformance: This cost is the cost of low quality, i.e., due to failures [7]. 


\section{Opportunity Cost Models by Carr}

Cost of conformance, Cost of non-conformance, and opportunity cost are included in this model.

1) Opportunity cost: Profit not earned owing to lost customers and a reduction in revenue because of nonconformance [17].

\section{Process Cost Model by Ross}

It is concerned with the process cost; that is why it distinguished from Crosby's model. It is the sum of the process cost of conformance and non-conformance. It is also called IDEF (the computer-aided manufacturing integrated program definition methodology) [20]

\section{E. ABC Costing Model by Cooper}

ABC model is not a CoQ model. However, Activity Based Costing model provides an alternative approach to quantifying activities' cost. The ABC model's goal is to eliminate Non Non-Value Added Activities and minimize the Value added activities to reduce total cost and gain maximum quality level by using minimum resources $[9,10,17,18,20]$.

\section{F. Taguchi's Quality Loss Function}

According to this loss function, once the product is shipped to the customer, the losses are discovered, some are tangible, and some are intangible. The loss perceived will be significantly higher due to hidden loss. It is given by the following function:

$$
\mathrm{L}=\mathrm{D}^{2} \mathrm{C}
$$

Where $\mathrm{D}=$ Deviation from the target, $\mathrm{C}=$ The Cost Factory would incur to achieve the target specifications, $\mathrm{L}=$ Actual Cost Loss [21].

1) Ice berg theory by defeo: Defeo explains that many costs are visible and can be determined, but there are several losses that are hidden just like this iceberg. After careful examination, we can determine the hidden losses which an organization suffers after the wrong shipment. We should take all these hidden measures in our COQ template to determine the hidden factors as much as we can [22].

\section{RESEARCH METHODOLOGY}

\section{A. The Company Case}

This study was conducted at a textile manufacturing company in Karachi, Pakistan. The case company manufactures and exports a wide range of towel products only such as Bath towels, Hand Towel, Kitchen Towel, etc. It has annual sales of around PKR 11B. Since the COQ was calculated for the data of six months, so half of the annual sales taken in the calculation. The target is to calculate the COQ for this unit for the six months data from May'18 to Oct'18).

\section{B. Data Collection}

The data collection was itself a challenging activity. Since personnel in the organization were not aware of the significance of COQ. So, they were reluctant to share their departmental information. The dedicated production professionals who got awareness took data from different departments like plant engineering, marketing, Chemical Laboratory, Quality Control, Finance, Human Resource, and Logistics when required. The data were evaluated by the Quality professionals to give direction to the team. The company provided data in the form of excel reports, and some were extracted from ERP (company's data module) generated PDF reports. The data was not synchronized as needed. Data was interrogated several times by COQ production teams individually; after that, it was arranged as per the desired format. It was also suggested the stakeholders to maintain the data as instructed in order to calculate COQ in the future.

\section{Prevention Cost}

Figure 1 shows the prevention cost elements of all the departments. We will be discussing each one of them one by one. Training has been taken in the Prevention cost because these training are on-ground training which are provided on a monthly basis to all the workers by the production supervisors. The trainers and trainees' training hours are expressed in the PKR. Maintenance Costs are the preventive maintenance costs, which include expenses of manpower, lubricants, and equipment costs.

Machines looms and Pits Cleaning are done to prevent product from contamination so the manpower utilized for cleaning are expressed in PKR. Yarn, Quality, Weight, and Accessories Verification are done in order to validate the parameters and to avoid mixing of materials. Beam Inspection is done to prevent damages of yarn and looms by the plant engineering department. The costs of manpower and beam repair equipment involved in preventing material from being damaged are expressed in PKR. Humidification and Blow off suction plant fulfill the purpose of maintaining the temperature and regular cleaning of looms; so it can work properly 24/7. These maintenance costs are taken from the Plant Engineering department in PKR. The culture of Quality Circle is present in the only Printing department. This team's wages include as per their contribution on average, and it is expressed in PKR. 


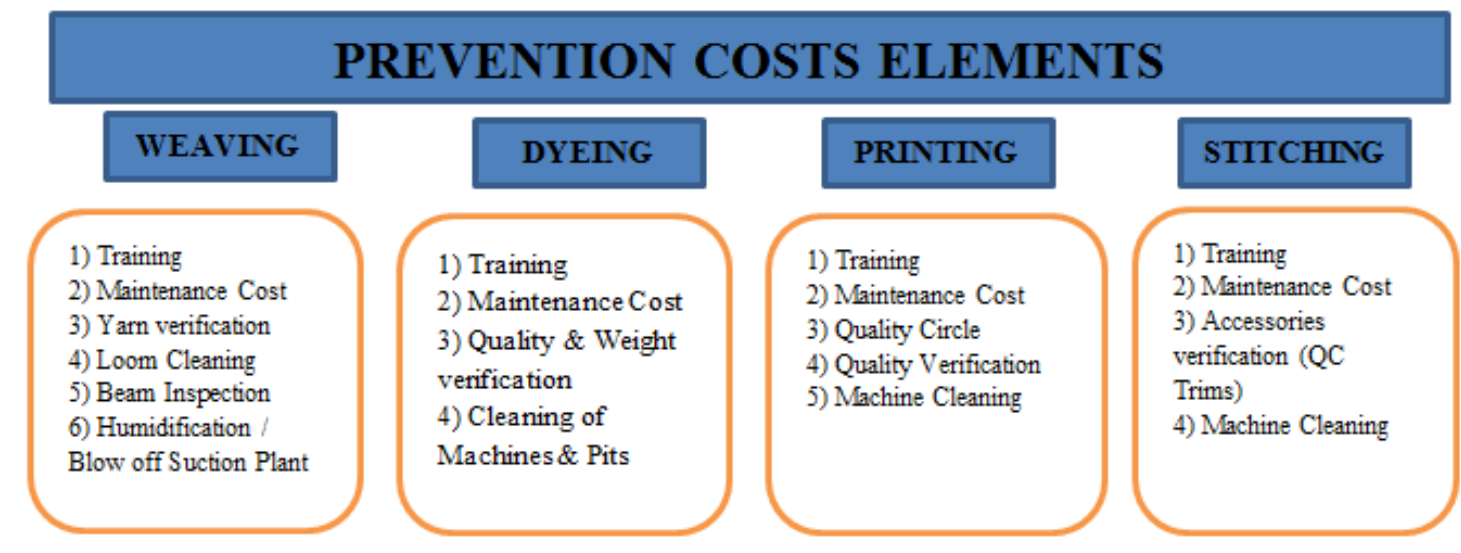

Fig. 1. Prevention costs elements department wise

\section{Appraisal Cost}

Figure 2 shows the cost elements of appraisal cost. We will discuss each aspect individually. QC inspection defines the quality of the product, so the manpower and equipment costs are taken in PKR. The calibrations are done from both means internal and external. These equipment and manpower costs are taken in PKR. The Loom Data System (LDS) and DCS Distributed Control System (DCS) need to be maintained. The wages of dedicated manpower are expressed in PKR. Loom Designer verifies the design on the loom, so the associated personnel wages are expressed in PKR. Internal Audits include IMS audit, HSE Audit, Risk and Environment Impact Assessment, $5 \mathrm{~s}$ audits, and technical Compliance audits are performed by QMS department. Their wages as per the department share are expressed in PKR. Lab Inspection means validation of the parameters of the fabric after every new lot. In case of outliers they contact concerned departments. Machine Chemist's duty is to check the parameters of the machines and fabric on the ground. Their wages as per department shares are expressed in PKR. Design Checkers are present in the printing department to validate the design of printing screens in the engraving department. The stitching department has additional manpower for inspection, which are deputed in Packing, metal detector, grading, and counter sections. Tomake sure the fabric is proper packed in the cartonsthe Fabric does not contain any metal part. The Counting of fabric is also done in order to make sure no wrong number of quantities is entered in the section. The graders check all the parameters as per the defect list. All of these additional inspection wages are included in appraisal costs and expressed in PKR.

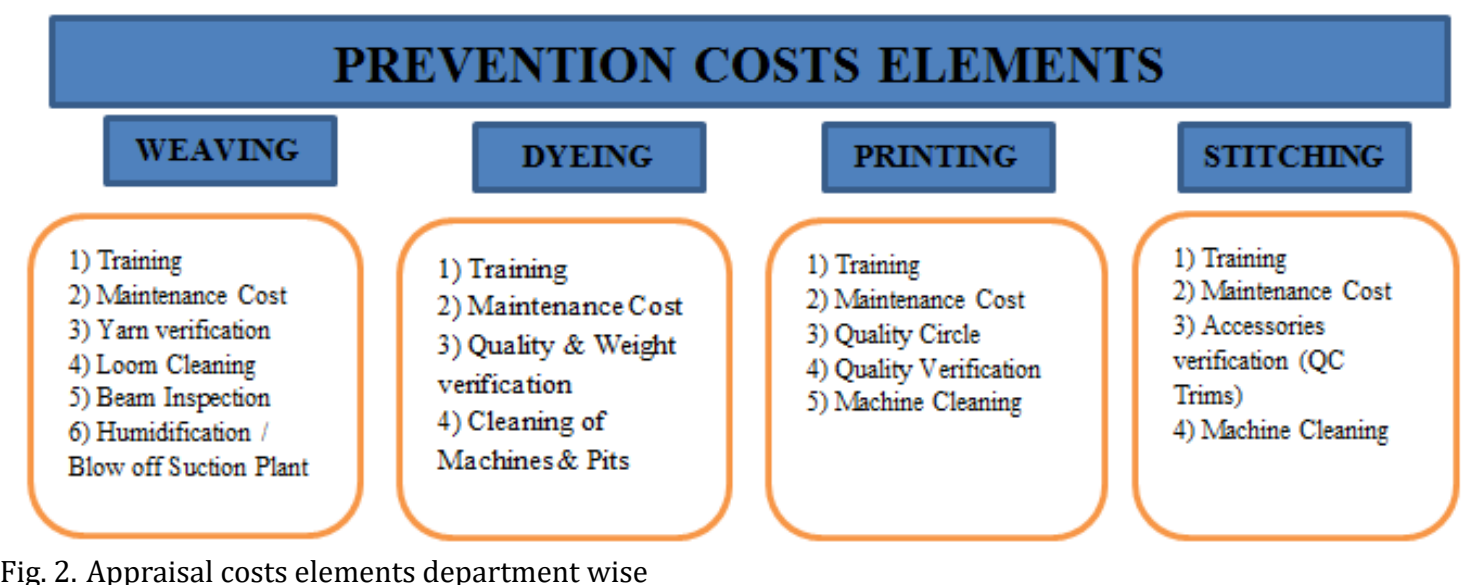

\section{E. Internal Failure Cost}

Figure 3 shows the internal failure costs elements. Rework cost in PKR is included as per the additional material lost to mend the fabric. Overtime, which is carried out due to rework and quality maintaining, had been taken from the $\mathrm{Hu}$ man Resource department in PKR. Productions Loss targets

which are unachieved due to downtime are converted into Kilograms, followed by PKR are included in internal failure cost. B \& C pieces are low-cost sale products. The loss is taken in PKR. Raw Material Wastage targets which are unachieved are taken in PKR. But the data shows all the targets are achieved in these six months. 


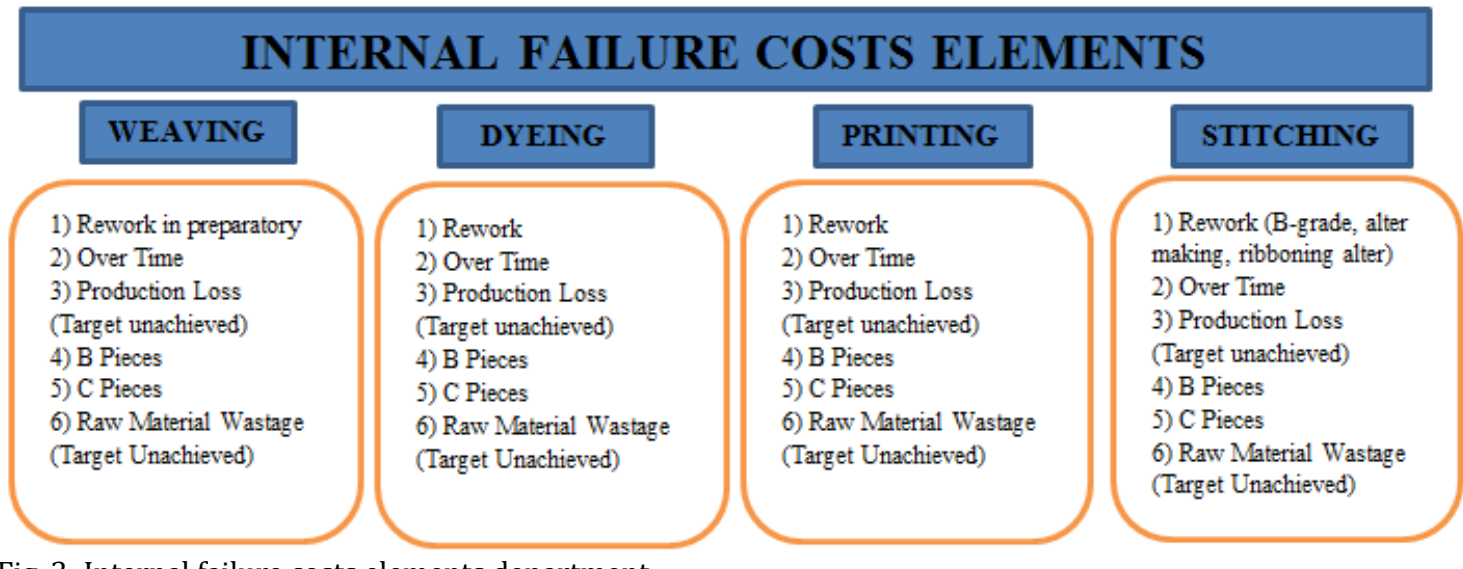

Fig. 3. Internal failure costs elements department

\section{F. External Failure Cost}

Figure 4 shows the external failure cost elements of all the departments. Since we are calculating COQ in the Textile sector, so there is no possibility of Warranty Cost, Service Cost, and Repair Cost. Our international customers do not found the returning fabric in case of customer dissatisfaction. So, as per the analysis we have two components in external failure that the company bears. Container Detention is external failure. The poor planning cause container to be detained, which results in late shipment of fabric. The department which is responsible for late shipment is recorded by the marketing department, and the PKR lost is added to this external failure. Late Shipments (Air Shipments) are held sometimes in order to deliver fabric urgently to the customers. Again, the department which is responsible for air shipment is added to the external failure costs.

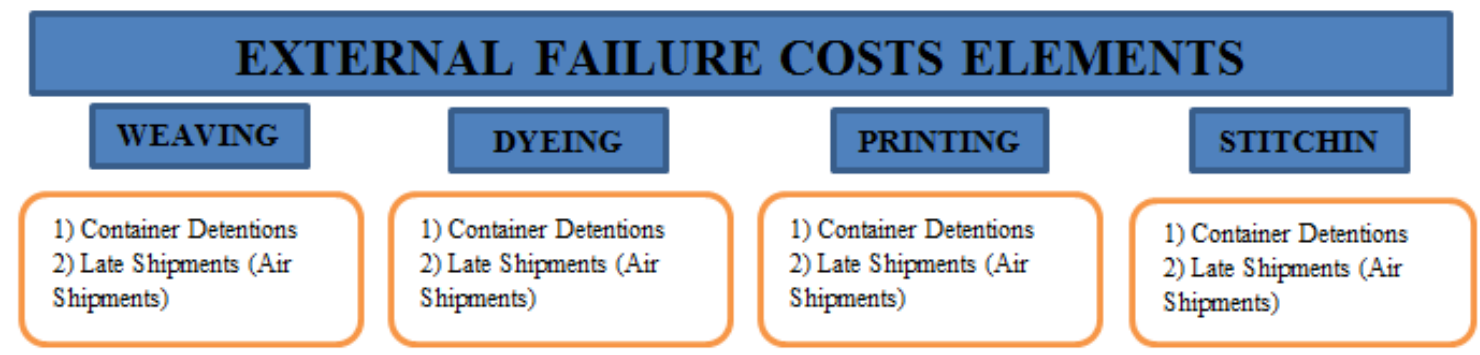

Fig. 4. External costs elements department wise

\section{G. Opportunity Cost}

Fig 5 shows the opportunity costs. The target unachieved is taken in internal failure cost, but there is a clear opportunity found if the performance improves, then we can go beyond the target. Production lost due to downtime can shrink as much as possible such that it can run on maximum capac-

ity which is beyond the company's target. The costs of lost Kilograms are expressed in PKR. Raw Material Wastage also has given targets in the organization. Fortunately, there is no excess loss of raw material; that is why it is not mentioned earlier in internal failure cost. But again, there is an opportunity to lose no raw material. The opportunity lost raw material fabric kilograms is expressed in PKR.

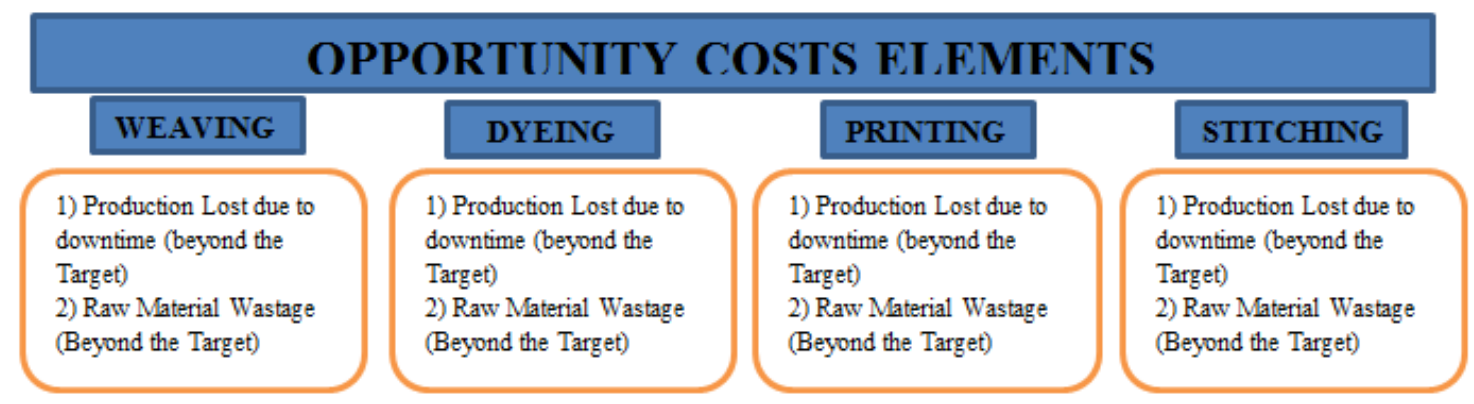

Fig. 5. Opportunity costs elements department wise 


\section{RESULTS AND DISCUSSION}

Cost elements from different departments were analyzed by quality professionals. We got calculations from four different departments. The calculated results of COQ from weaving, dyeing, printing department are shown in Figures 6, 7, 8 , and 9. We found one thing similar in all graphical figures. That internal Failure Cost is found to be Maximum in all graphical figures.

Weaving COQ in Figure 6 shows that internal Failure cost is the highest. But External Failure Cost is the lowest, which is suitable. Since we are working to reduce total COQ, so internal failure cost and opportunity cost must be reduced. Dyeing, printing \& Stitching COQ in Figures 7, 8, and 9 respectively show the almost same trend. However, some showed higher external failure and appraisal failure cost as compared to prior graphical figures. Again, in order to see a drastic reduction in COQ, we should reduce internal failure cost as our first priority. It is also observed that by calculating each COQ, we can see a clear picture of every department. If we directly combine all the costs, then we cannot see a more accurate picture and situation of every department. It is noted that the price of conformance is not effective and it should be increased.

Because it is evident from $\mathrm{COQ}$ calculated in the different sector shows that COGQ is 22 to 50 times is cheaper than COPQ [23].

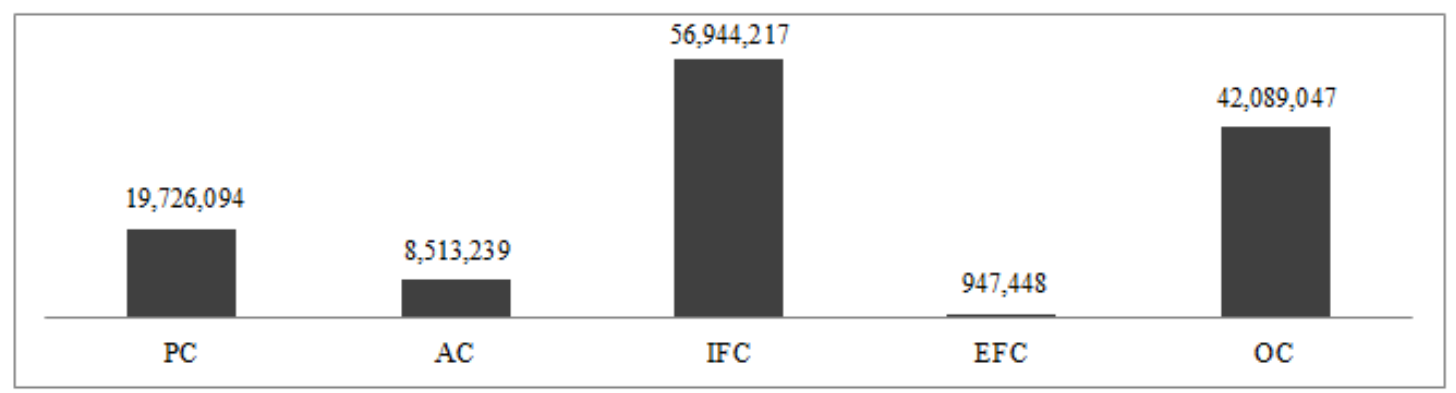

Fig. 6. Weaving COQ in PKR

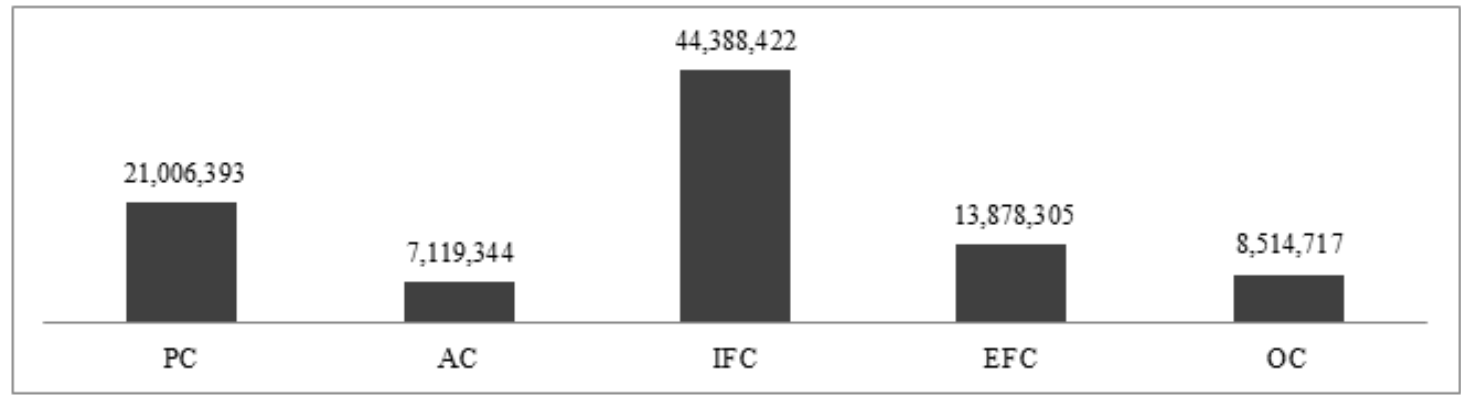

Fig. 7. Dyeing COQ in PKR

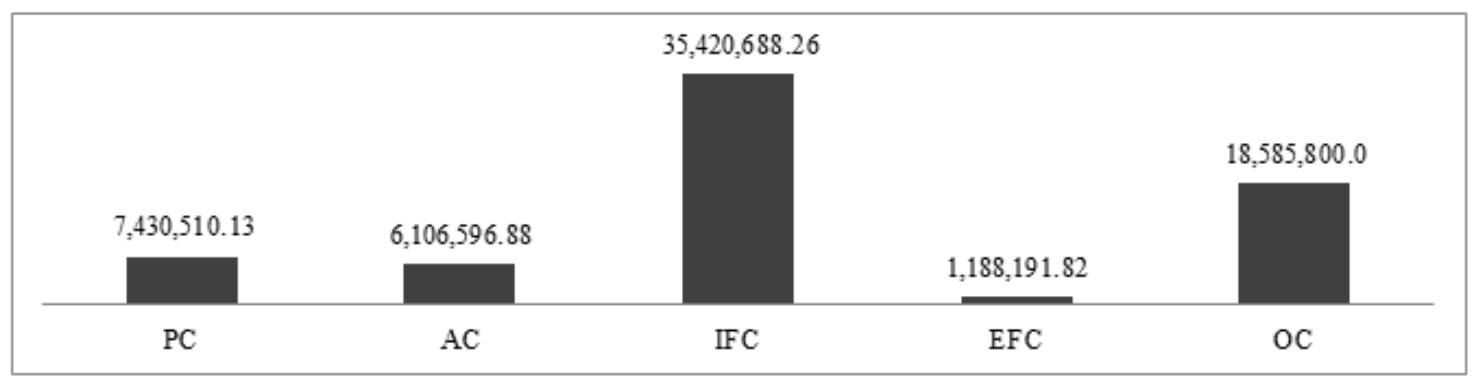

Fig. 8. Printing COQ in PKR 


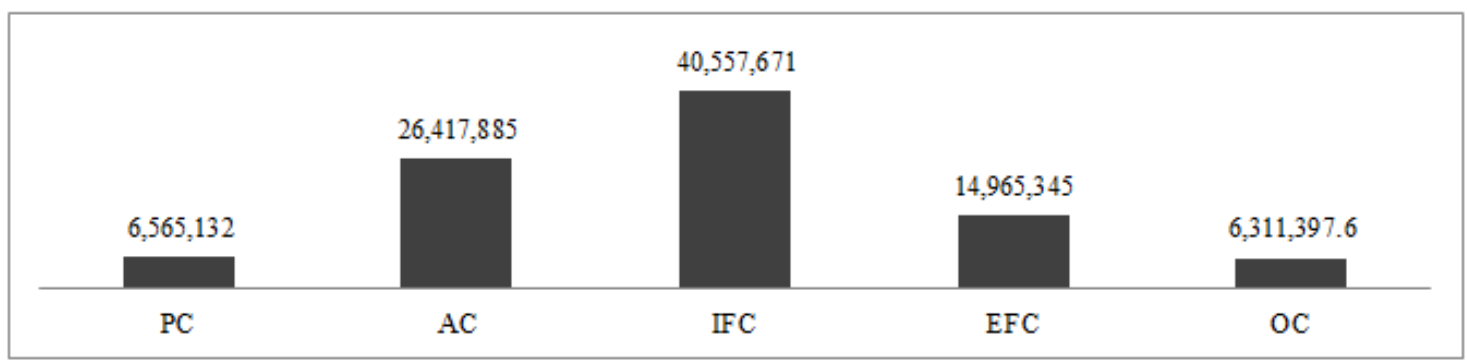

Fig. 9. Stitching COQ in PKR

It was suggested that there should be one template for all the departments in order to avoid any ambiguity in the future calculation of COQ. The consolidated cost elements are shown in Table 1. Every department will follow this table and calculate its COQ to compare the COQ trend from the previous one. The step by step procedure for calculating COQ is attached at the end of this paper. Then, after the calculation of individual COQ, all will be consolidated in one table such that Table 2 .

TABLE 1

CONSOLIDATED COST ELEMENTS OF ALL DEPARTMENTS

\begin{tabular}{|c|c|}
\hline Cost Category & Cost Elements \\
\hline \multirow[t]{2}{*}{ PREVENTION COST } & Training/Quality Circle \\
\hline & Overall Maintenance Cost/Beam Inspection \\
\hline \multirow[t]{2}{*}{ Cost/humidification (utility cost) } & Loom/pit/SOHLER/machine cleaning \\
\hline & Quality/Weight/yarn/Accessories verification \\
\hline \multirow[t]{6}{*}{ APPRAISAL COST } & $\mathrm{QC} /$ Lab inspection \\
\hline & Calibration cost \\
\hline & DCS/LDS/metal detector, Maintenance Cost \\
\hline & Internal Audit Cost \\
\hline & Process Manpower inspection cost (Machine \\
\hline & $\begin{array}{l}\text { Chemists, Loom designer, sub-store, grading, counter, } \\
\text { design check, shade) }\end{array}$ \\
\hline \multirow[t]{6}{*}{ INTERNAL FAILURE COST } & B Pieces \\
\hline & C Pieces \\
\hline & Overtime for rework and quality maintaining \\
\hline & Production Loss (target unachieved due to downtime) \\
\hline & Rework \\
\hline & Raw Material Wastage (Target Unachieved) \\
\hline \multirow[t]{2}{*}{ EXTERNAL FAILURE COST } & Container Detention \\
\hline & Late Shipments (Air Shipments) \\
\hline \multirow[t]{2}{*}{ OPPORTUNITY COST } & Production Lost due to downtime (beyond the Target) \\
\hline & Raw Material Wastage (Beyond the Target) \\
\hline
\end{tabular}


TABLE 2

CONSOLIDATED CALCULATION OF COST ELEMENTS OF ALL DEPARTMENTS

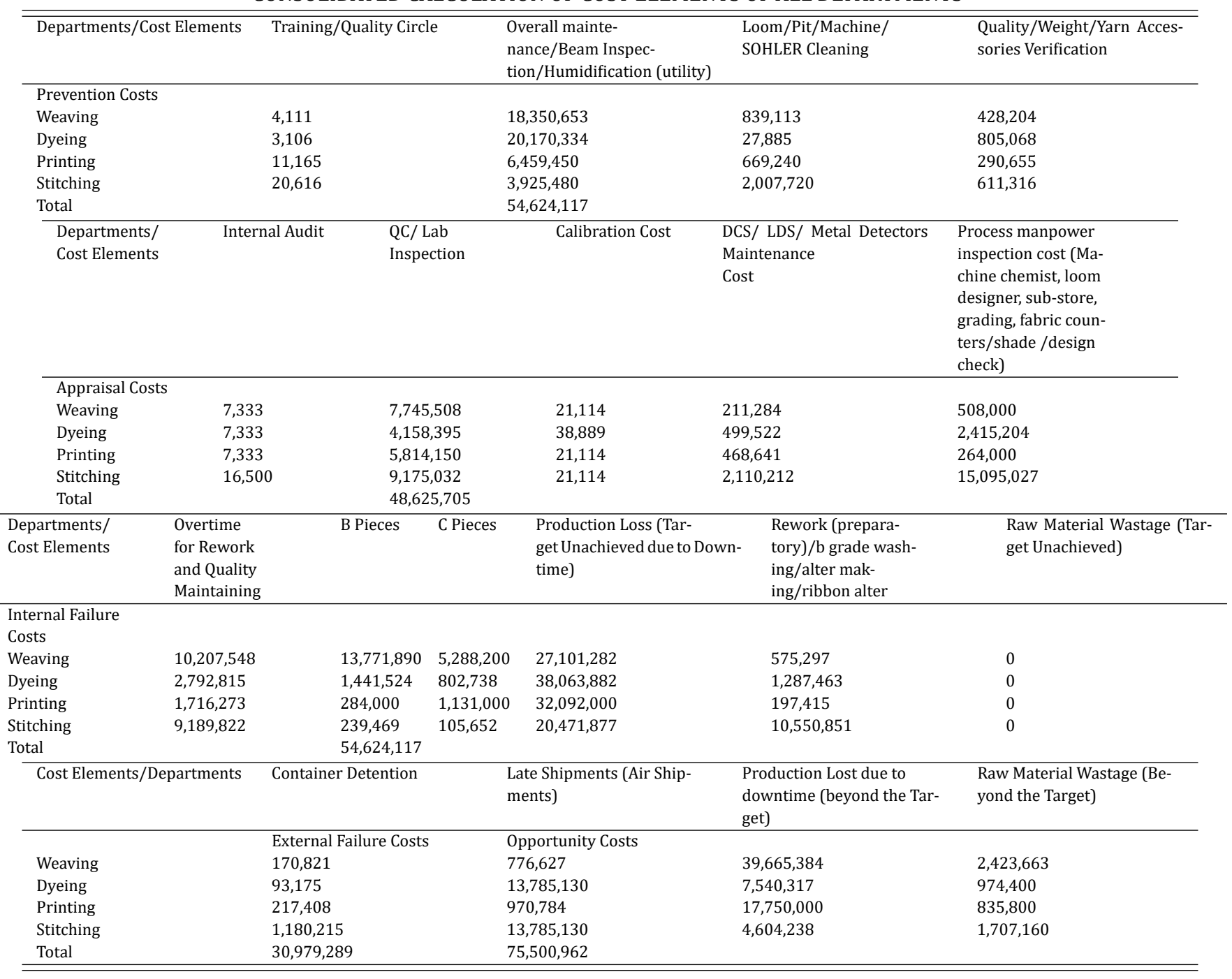

\section{COQ SIX MONTHS DATA (PKR)}

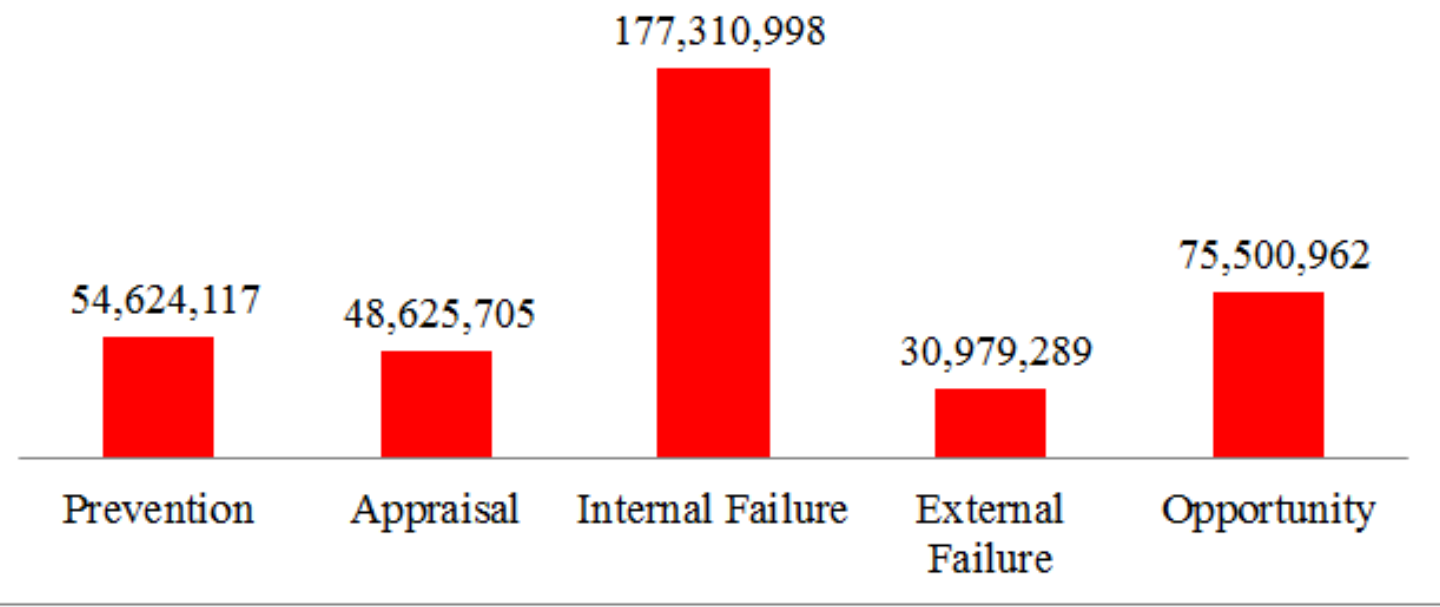

Fig. 10. Total COQ in PKR 
Table 2 shows all the calculated values department wise, and its graphical form is shown in Figure 10 and Figure 11.
Internal Failure Cost is found to be $46 \%$ of COQ. It should be further investigated to reduce total COQ.

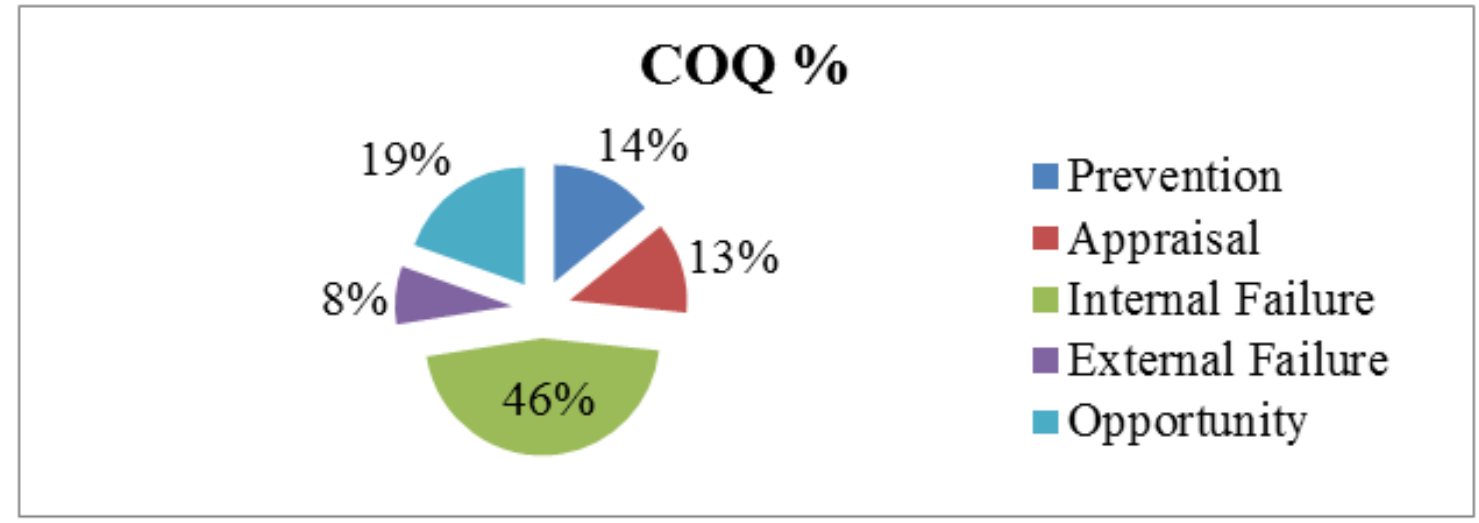

Fig. 11. Total COQ in \%

\section{A. Quality Index}

The quality index is the ratio of total quality costs and the total Sales. And it is found to be $6.8 \%$, as shown in Table 3 . As per the pioneer's approach, the COQ\% of sales should be between 2 to $4 \%$. [7, 24, 25]. The internal failure cost is $3.11 \%$ of the total sales, which is itself alarming and also confirms that the main culprit is IFC. So, how to reduce Internal Failure Cost will be discussed in this paper later.

TABLE 3

3 (ACTUAL COQ\% W.R.T. SALES)

\begin{tabular}{ll}
\hline \hline Total Sales of six months & $5,683,547,319$ \\
Total COQ of six months & $387,041,072$ \\
$\%$ & $6.8 \%$ \\
\hline \hline
\end{tabular}

\section{B. Pareto Analysis of Internal Failure Cost}

It is shown in Figure 12 that main causes for internal failure cost are Production Loss and Overtime. The production Loss is the target unachieved due to downtime; for that reason, overtime of workers to achieve the target and maintain quality takes place. So, both the major reason, according to the $80 / 20$ rule, is connected. If downtime will not occur, then there would take any overtime because all tasks would be performed in time. So the major reason is the first one, which is production Loss (target Unachieved).

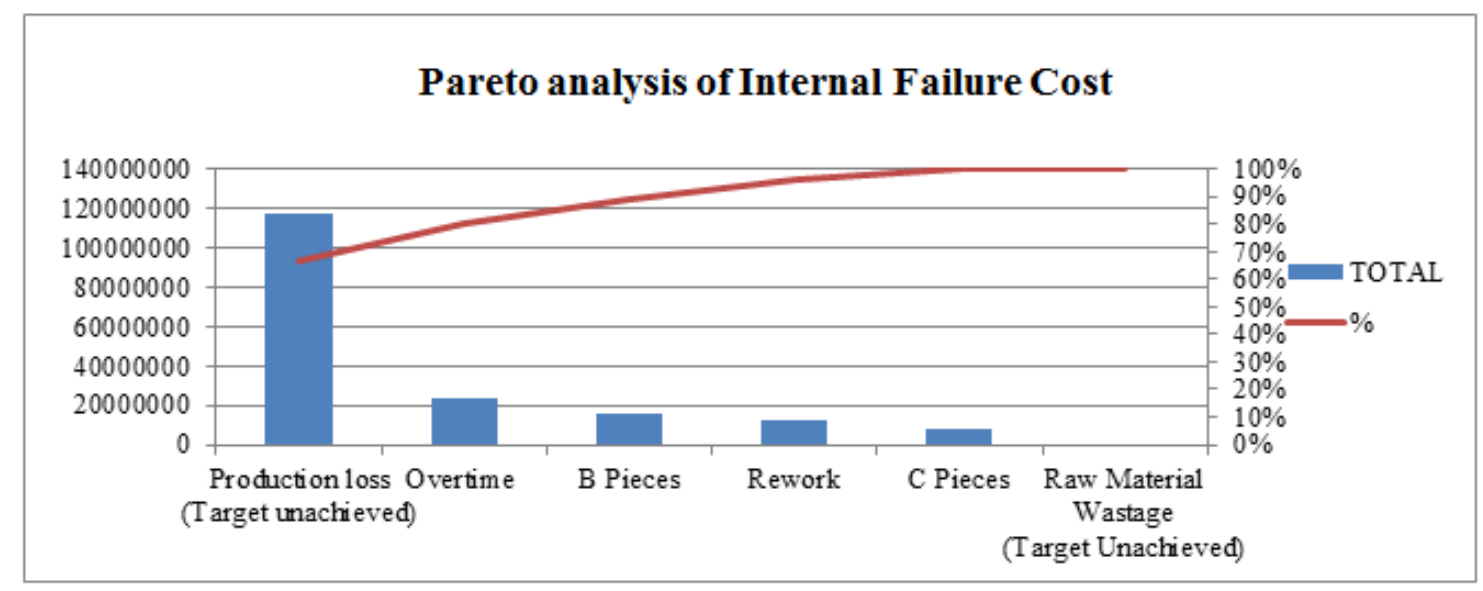

Fig. 12. IFC pareto analysis 


\section{Why-Why Analysis of the Most Critical Highlighted by Pareto}

Analysis 1 below showed that the major reason for production loss (target unachieved) was the energy crisis; it was earlier highlighted in the above heading 2.7 that right now textile has been facing gas and electric load shedding. The analysis also states that there is a need for lean thinking and sound maintenance techniques.

\section{Why-Why Analysis}

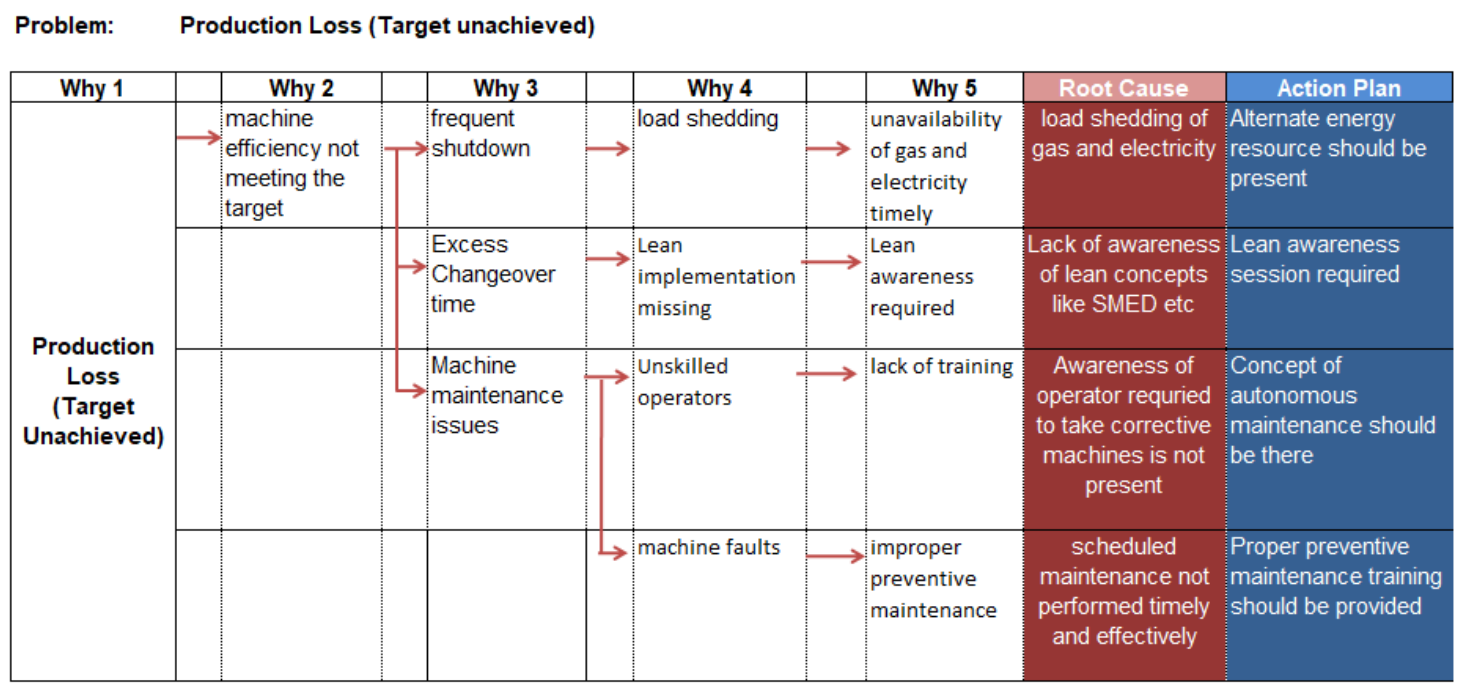

Fig. 13. Why-why analysis

\section{Implementation of the Highlighted Causes}

Firstly, it was suggested that higher management to support us in developing lean thinking in the organization. They supported us; we started a training session for the work- ers and their supervisors as they are dealing with products directly on the production floor. Pictures 1 and 2 show the training session provided to management staff \& picture 3 and 4 shows the training session provided to nonmanagement staff.

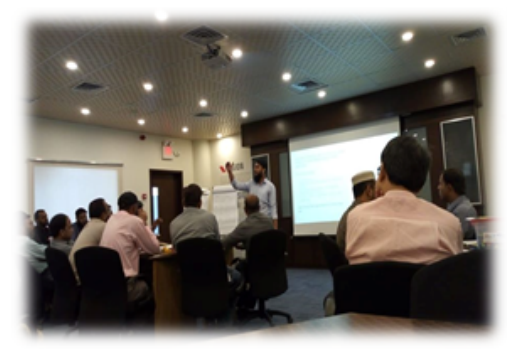

Picture 1

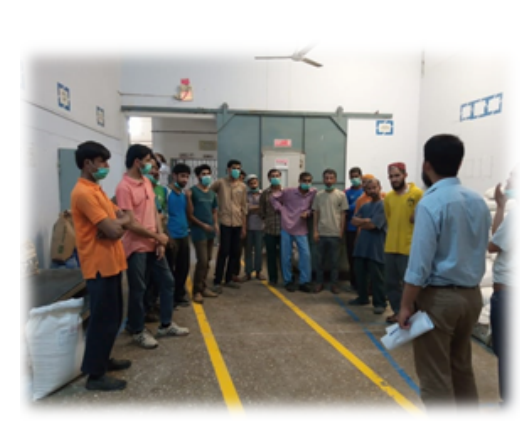

Picture 3

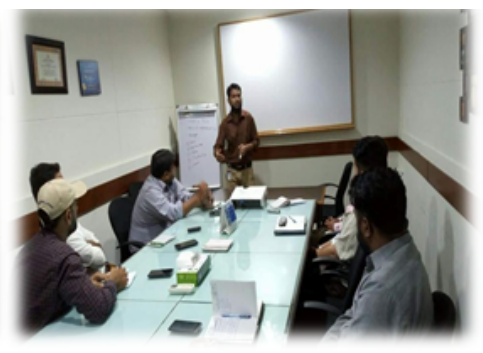

Picture 2

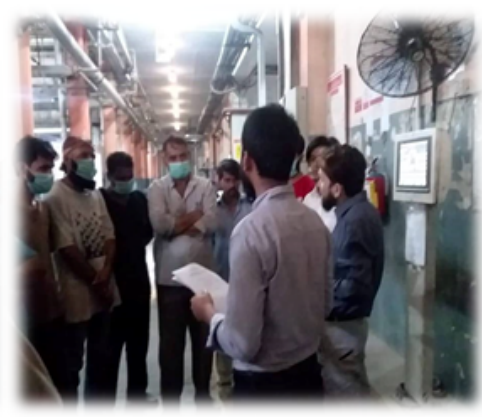

Picture 4

Fig. 14. Non-management staff 
Secondly, the major reason for high COQ was the load shedding of electricity and gas. We already know that gas and electricity load shedding is inevitable and it needs to be resolved by the factory's management. The higher management is reluctant to invest in the self-produced energy initiatives due to a huge amount. We convinced factory management that this would be one-time investment, and it would give you benefit in the long term. The factory management agreed somehow; they took solar and coal gener- ation initiatives, which would feed energy to those departments that have had the potential to produce the maximum amount of products.

\section{E. Results after Implementation of the Suggestions}

The COQ calculated for the other six months for the 2nd time for the same textile unit. After taking some sustainable and lean initiatives, the total COQ reduced from $6.8 \%$ of sales to $4.5 \%$ of sales, as shown in Figure 15 below. We found a profit of 118637647 PKR in this calculation for six months.

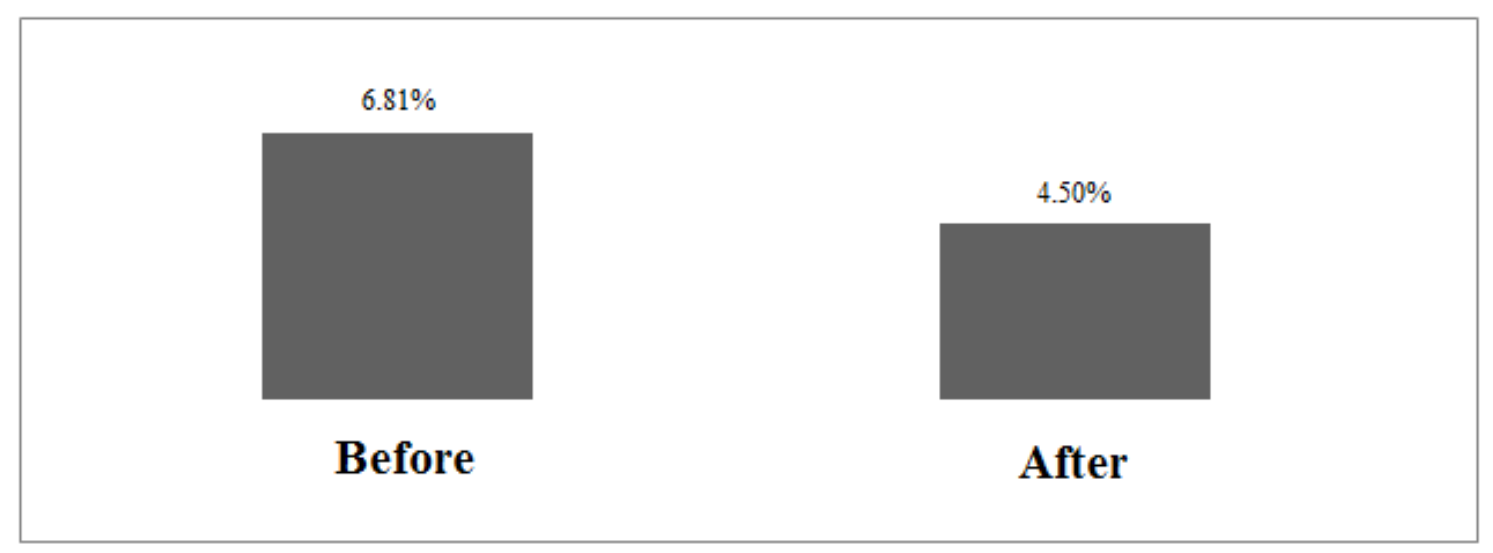

Fig. 15. \% reduction in COQ after improvement

\section{CONCLUSION}

This paper describes the background and the challenges that have been faced by the textile sectors in Pakistan with the help of a study done earlier. Cost of Quality was implemented in a towel products manufacturer, which is itself an achievement. This research paper provides a case study on how to reduce COQ in any sector, especially in textiles. In this case study, the internal failure cost is the highest cost, and the major reason is the production loss (target unachieved). We did Pareto analysis to find out the most critical cause, and then we did a why-why analysis to find out the root cause of production loss. This case study shows the reduction of COQ from $6.8 \%$ to $4.5 \%$ of sales after the implementation of sustainability and lean initiatives.

This paper also developed a culture of lean as a literature review highlighted that there is a lack of a lean approach in the textile industry. The COQ is an iterative method, and it can be used repeatedly. The result still shows that COQ can be reduced further if the organization takes lean initiatives on priority and provide further awareness of lean-to every department. They can tell us better ways to maximize profit. Moreover, the study was carried out in the developed textile industry of Pakistan. This can be carried out in every textile industry and can reduce the manufacturing cost by applying COQ techniques.

\section{REFERENCES}

[1] M. K. Omar and S. Murgan, "An improved model for the cost of quality," International Journal of Quality \& Reliability Management, vol. 31, no. 4, pp. 395-418, 2014. doi: https://doi.org/10.1108/IJQRM-05-2012-0066

[2] S. M. Qureshi, S. Majeed, and R. Khalid, "Where do we stand in cost of quality awareness? Pakistan's case," International Journal of Quality Engineering and Technology, vol. 4, no. 4, pp. 273-289, 2014. doi: https://doi.org/10.1504/IJQET. 2014.066989

[3] T. M. Malik, R. Khalid, A. Zulqarnain, and S. A. Iqbal, "Cost of quality: Findings of a wood products' manufacturer," The TQM Journal, vol. 28, no. 1, pp. 2-20, 2016. doi: https://doi.org/10.1108/TQM-01-2014-0014

[4] A. Chopra and D. Garg, "Introducing models for implementing cost of quality system," The TQM Journal, vol. 24, no. 6, pp. 498-504, 2012. doi: https://doi.org/10.1108/17542731211270061 
[5] S. Özkan and Y. Z. Karaibrahimoğlu, “Activity-based costing approach in the measurement of cost of quality in SMEs: A case study," Total Quality Management \& Business Excellence, vol. 24, no. 3-4, pp. 420-431, 2013. doi: https://doi.org/ 10.1080/14783363.2012.704286

[6] R. M. Moen, "New quality cost model used as a top management tool," The TQM Magazine, vol. 10, no. 5, pp. 334-341, 1998. doi: https://doi.org/10.1108/09544789810231216

[7] P. B. Crosby, Quality is Free: The Art of Making Quality Certain. New York, NY: McGraw-Hill, 1979.

[8] J. Marsh, "Process modeling for quality improvement," in Proceedings of the Second International Conference on Total Quality Management, California, CA, 1989.

[9] A. Schiffauerova and V. Thomson, "A review of research on cost of quality models and best practices," International Journal of Quality \& Reliability Management, vol. 23, no. 6, pp. 647-669, 2006. doi: https://doi.org/10.1108/ 02656710610672470

[10] A. V. Feigenbaum, "Total quality-control," Harvard Business Review, vol. 34, no. 6, pp. 93-101, 1956.

[11] R. Jaleel, A. Ishfaq, A. Saleemi, and T. Samin, "Swot analysis of textile industry in Pakistan," Asian Journal of Research in Business Economics and Management, vol. 4, no. 9, pp. 76-87, 2014. doi: https:doi.org/10.5958/2249-7307.2014. 00916.5

[12] M. Ataullah, A. Sajid, and M. Khan, "Quality related issues and their effects on returns of pakistan textile industry," Journal of Quality and Technology Management, vol. 10, no. 1, pp. 69-91, 2014.

[13] I. U. Hasan, M. M. Sohail, J. L. Piracha, and K. Ahmad, "Implementation status of TQM practices in textile and apparel industrial organization: A case study from Faisalabad, Pakistan," Journal of Economics, Management and Trade, vol. 3, no. 3, pp. 201-223, 2013. doi: https://doi.org/10.9734/BJEMT/2013/3161

[14] M. Ramzan, S. M. Qureshi, M. Ullah, M. Memon, and M. Siddiqui, “Assessment of the extent of implementation of Quality Management System (QMS) and Cost of Quality (COQ) concepts: A case from a developing country," The Journal of Engineering Research, vol. 14, no. 2, pp. 145-155, 2017. doi: http://dx.doi.org/10.24200/tjer.vol14iss2pp145-155

[15] M. Shafiq, "Implementation of quality management systems and business excellence frameworks in Pakistani textile companies," Journal of Quality and Technology Management, vol. 7, no. 2, pp. 11-23, 2012.

[16] M. Fatima and E. Ahmed, "Quality management in Pakistan's knitwear industry," Quality Engineering, vol. 18, no. 1, pp. 15-22, 2006. doi: https://doi.org/10.1080/08982110500403490

[17] L. P. Carr, "Applying cost of quality to a service business," Sloan Management Review, vol. 33, no. 4, pp. 72-80, 1992.

[18] J. Juran and F. Gryna, Juran's Quality Control Handbook. New York, NY: McGraw Hill, 1951.

[19] Y. L. Chia, Y. L. Jia, and I. C. Ray, "Improve quality and efficiency of textile process using data-driven machine learning in industry 4.0," International Journal of Technology and Engineering Studies, vol. 4, no. 1, pp. 64-76, 2018. doi: https: //doi.org/10.20469/ijtes.4.10004-2

[20] R. Cooper, "The rise of activity-based costing-part four: What do activity-based cost systems look like?" Journal of Cost Management, vol. 2, no. 2, pp. 4-14, 1989.

[21] G. Taguchi and D. Clausing, "Robust quality," Harvard Business Review, vol. 68, no. 1, pp. 65-75, 1990.

[22] J. Defeo, The Tip of the Iceberg', Quality Progress. Milwaukee, WI: ASQ Press, 2001.

[23] S. R. Ashraf, "Compare cost of good quality \& cost of poor quality and have a wise decision: A study from automobile industry of Pakistan," Journal of Business and Management, vol. 17, no. 9, pp. 19-28, 2015. doi: http://hdl.handle.net/ $123456789 / 3355$

[24] M. R. Ostrenga, "Return on investment through the cost of quality," Journal of Cost Management, vol. 5, no. 2, pp. 37-44, 1991.

[25] D. Hansen, M. Mowen, and L. Guan, Cost Management: Accounting and Control. Mason, OH: Cengage Learning, 2009. 